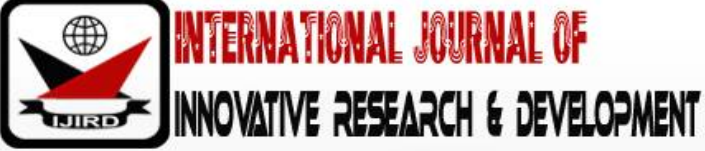

ISSN 2278 - 0211 (Online)

\section{Hands-On Activities on Dagomba Bim’ Mayli Production among Elective Class Students in E.P College of Education, Bimbilla, Ghana}

Mumuni Zakaria Fusheini
Tutor, Department of Vocational Skills, E.P College of Education, Bimbilla, Ghana
Dr. Joe Adu-Agyem
Senior Lecturer, Department of Educational Innovations in Science and Technology, KNUST, Ghana
Dr. Eric Appau Asante
Senior Lecturer, Department of Educational Innovations in Science and Technology, KNUST, Ghana

\begin{abstract}
:
The study aimed at providing teacher trainees in Evangelical Presbyterian College of Education, Bimbilla, Ghana to learn how to produce the Dagombas' Bim' mapli cloth as a requisite requirement for their second semester course of study on Weaving and Stitching. For the purpose of this article, the word 'smock' is referred to as Bim'mayli in the context of the Dagombas' culture. The study also aimed at fostering creative entrepreneurial skills in the teacher trainee to be able to generate Bim'manli weaving enterprises as a supplement to their teaching profession. A total of 86elective class students and 10 traditional Bim'mayli weavers among the Dagombas were selected by the use of purposive sampling technique. The 86 teacher trainees were guided on how to prepare yarns on bobbins for warping and finally mount the warp beam on the Dagombas' traditional loom for weaving the Bim'mayli. Interviews were conducted among the 86 teacher trainees to acquire data on the students' demography and their previous requisite skills in the weaving of any traditional cloth in Ghana which include kente, kete and the Bim'mayli. Observation was used to obtain data by noting down teacher trainees' interactions with the loom and its accessories. Observation was again used to take notice of the nature of woven Bim'mayli cloth by the teacher trainees. Findings revealed that majority of the teacher trainees did not have prerequisite knowledge or skills in weaving of any traditional cloth in Ghana. Interview granted to 10 traditional Bim'manli weavers indicated that the weaving of the Bim'manliwas practiced among males and females in the olden days.However, males were and have been the majority of weavers. Majority of the teacher trainees were Dagombashence they had some knowledge regarding the names of the parts and accessories of the traditional loomfor weaving the Bim'maylicloth. The study, therefore, guides the teacher trainees throughout the production processes involved in weaving the Bim'mayli in Northern Region of Ghana.
\end{abstract}

Keywords: Elective, Bim'ma $l i$, hands-on-activities, weaving, Bim'manli cloth, warping, reeding, heddling

\section{Introduction}

The study seeks to foster creative entrepreneurial skills among the teacher trainees offering elective course in weaving the Bim'mayli cloth under the art component of Weaving and Stitching studied in Colleges of Education, Ghana. Teaching and learning in Colleges of Education (CoE) includes the study of art which seeks to provide the education of the head, hand and heart. In the second year courses, art remains an elective subject in which every college is destined to teach one practical course area where the teacher trainees are taught how to create three-dimensional art objects (Fiadzo, 2010).

Weaving and Stitching is the component chosen in E.P College of Education, Bimbilla and according to Ghana Education Service (2012), weaving and stitching aims at fostering creative skills of weaving and stitching in the teacher trainee to be able to teach art at the basic schools in Ghana. The weaving of the Dagomabas' Bim'manli cloth is a major traditional occupation among the people in the North (Abugri, 2017) and most of the teachers find it an appropriate supplement to their teaching professions when they are greatly seen by their looms during weekends and holidays weaving strips of Bim'manli cloths. The Bim'manli cloth is woven on the traditional loom and the production techniques are similar with the kente and kete weaving among the Asantes and Ewes respectively. The indigenous production stages of the Dagomba Bim' mayli cloth weaving starts from ginning of cotton to the last stage of weaving the long-stretched warp beam on the loom. However, modern productions of the Bim'mayli cloth starts from the preparation of bobbins with the total neglect of ginning, carding, roving and spinning before bobbins preparations are carried out. 


\section{Literature Review}

\subsection{Origin of Smock (Bim'mayli) Weaving among Dagombas}

The smock is a traditional Ghanaian dress made from cotton, wool and rayon. It is basically hand woven and hand sewn. The dress is worn for many purposes. They are worn for entertainment, funerals, festivals as adornment, war and among others (Abugri 2016). The word 'Batakari' is a Hausa palance which literally stands for 'out gown'. This indicates that Batakari as an exterior noble-like garment is worn over inner garments. The Batakari was normally embroidered with fancy designs especially at the front party (Essel \& Amissah 2015; News Ghana 2015). Batakari may consists of a flowing outer garment, long sleeves, inner robe and a trouser collectively known as three piece wear. "Fugu" also means cloth in Moshi language. It describes a variety of loose garment sewn from strips of cloth woven on the traditional looms in northern Ghana (Jasmine 2013).

The origin of the Dagomba Bim'ma liis trace able to different ethnic societies. One school of thought indicates that the Bim'mayli originated from Tang people, a village under Karaga district in the northern region (Essel \& Amissah 2015). Tettehfio (2009) also indicates that the Moshi ethnic society from the Burkina Faso who migrated to settle in the north arrived with the art. Similarly, Essel and Amissah (2015) state that; 'Others maintain that the part of the Mossi ethnicity in Burkina Faso who migrated to settle in Northern Ghana came with the craft' (pp 33-34). Tettefio (2009) also opines that the Moshi people from Burkina Faso were in the past, practising barter trade system from Upper Volta to the North and this clearly indicates that the Moshi people have had earlier contact with Dagombas.

Heathcote (2013) cited in Essel and Amissah (2015) justifies that from about $8^{\text {th }}$ Century A.D., the Hausa people from Nigeria were well established in the marketing of hand-woven cloths in the West African diaspora. Allman (n.d) cited in Essel and Amissah (2015) stresses that the Mossi business men and women were probably first custodians of the Bim'manli weaving craft in the lands of Ghana.Essel and Amissah finally posited that the smock culture and art gained fame among ethnic societies in the three Northern Regions of Ghana because of possibilities in acculturation, enculturation, and transculturation of smock weaving.

\subsection{Definition of Weaving}

TEonline (2016) purports that one major technique for making fabrics or cloths globally, is by weaving. In the weaving industry, two separate sets of yarns known as the warp and the filling or weft are intertwined with each other to make a fabric. Similar to the method of weaving are felting, braiding or plaiting and knitting (Fiadzo, 2009). Yarn is a long continuous length of interlocked fibres. The warp refers to the lengthwise or longitudinal yarns and they run from the back to the front of the loom. The crosswise or lateral yarns are the filling or weft. According to TEonline weft or woof is an old English word referring to that which is woven. It an obvious observation that the characteristic of any woven cloth largely depend on the method employed in interweaving the two sets of threads.

Bim'mayli cloth is indigenously woven on the Dagomba traditional loom which is a wooden constructed mechanism for holding the warp threads in place while the filling threads are woven through them using the shuttle. Natural fibers like cotton, wool and silk and synthetic fibres such as nylon and Orlon are commonly used to prepare yarns for weaving smock and other textiles (Frimpong \& Asinyo 2013). Other fibers can and are also used for weaving. Yarn to be used as the warp goes through operations such as spooling, warping and slashing to prepare them to withstand the strain of the weaving process.

\subsection{Strip Weaving}

There a lot of strip weaving traditions in West African diasporas. Strip weaving is seen from Senegal in the west to Cameroon in the east, and from the edge of the South Sahara to the coast (Frimpong \& Asinyo 2013). Strip-woven cloth is in most cases made by men on narrow double-heddle looms with mostly two or four heddles. With technological advancement, most traditional looms for strip weaving such as those used by the Asantes and Ewes in Ghana are designed with up to six heddles which allow the weaver to create more intricate structures such as variations of twill weave. However, strip weaving of Bim'ma $l i$ cloth in Northern Ghana uses only two heddles and is plainly woven. They weave a continuously long, narrow band of cloth, and then sewn them together side by side by stitching to produce one large piece of cloth or dress (News Ghana 2016). In some cases, the weavers will dye the yarns before pooling or warping in order to add patterns, textures, and colours to the strips (Frimpong \& Asinyo 2013; News Ghana 2016).

In Ghana, not all woven cloths are incorporated with symbols at the weaving stage. The incorporation of symbols or motifs into the weave is mostly seen among the Asantes and Ewes' weavers who skillfully weave adinkra symbols and totemic animals into cloth (Sabutey 2009), meanwhile Bim'ma $l i$ woven strips from Northern Ghana are typically plain weave without the incorporation of symbols. However, symbols or motifs are later on embroidered onto the Bim'ma ${ }^{\prime}$ i during sewing by special Bim'mayli designers (Abugri 2017; Essel \& Amissah 2015).

These elements incorporated into the weave by the Asantes and Ewes' strip-cloth weavers are frequently very skillfully planned to give the final cloth a distinctive overall design. The names of woven cloth types are uniquely proposed by the overall quality of the cloth or the warp-strip pattern (Avins \& Quick 1998, cited in Frimpong \& Asinyo 2013).

\subsection{Weaving Operations}

Some authors including (Onder \& Omer n.d; TEonline 2016; Unal n.d) mention four main operations that are involved in weaving and these operations include Shedding, Picking, Beating up (Battening) and Taking up and Letting off. Contrarily, Onder and Omerhave rather specifically outlined five main operations by making each of take-off and left-off motions to stand as individual motions. The motions are as follows: 


\subsubsection{Shedding}

This is the process of separating the warp threads into two layers to form a tunnel known as the shed. This is done by the lowering and raising of the heddles through the peddles. In the Dagombas' loom, the treadles are made of simply flexible sticks tied to the heddles with cords.

\subsubsection{Picking}

It is the art of passing the weft threads through the shed. In the weaving process, immediately the gab (shed) is created by the lowering and rising of the warp, a yarn is inserted through the shed by a carrier device known as the shuttle. According to TEonline (2016), there are different types of devices used in propelling the filling yarn through the shed and this also depends on the type of loom used. This is because there are shuttle looms, shuttle less looms, circular looms etc. However, all the traditional looms of the Dagombas weavers are shuttle looms.

\subsubsection{Beating up (Battening)}

Unal (n.d) opines that with each picking operation, the reed is used to beat each newly inserted weft to the fell of the cloth. A reed is a comb-like structure attached to the looms and it is made up of dents (holes of the reed). Beating with the reed gives the fabric a firm, compact construction. In the Dagombas' Bim'mayli production, beaten is done with the reed on the loom and after the cloth beam is detached from the loom, a wooden hammer is again used to beat the cloth which gives it a smooth and lustrous texture. These three motions-picking, shedding and beating up are known as the primary motions on the loom.

\subsubsection{Taking Up and Letting Off}

Frimpong and Asinyo (2013) explain that when there is enough length of the newly woven cloth, the cloth must be wound on the cloth beam which is called 'taking up'. The action of the taking up motion also allows the warp yarns to be released from the warp beam to the 'weaving zone' which is called 'letting off'. For Bim'manli cloth weaving, the operations involved are shedding, picking, beating up, taking off and letting off motions. The mechanisms involved in the various operations are similar with kente weaving except that the heddles are two for Bim'manli and four to six heddles for Kente.

\subsubsection{Weaving Technique of the Bim'manli Cloth}

Several weaving techniques exist for weavers to choose from. The list includesplain, twill, sateen and satin weaves. But with the Dagomba Bim'ma licloth, the woven structure is purely plain weave.

\subsubsection{Plain Weaves}

Plain weave, as explained by Textile Fashion Study (2012), is the simplest and remains the mostcommon of all woven structures. It allows the maximum amount of interlacing of thewarp and weft and so for the same set of yarns, a fabric produced from plain weave willhave greater solidity and firmness than fabrics produced from any other weave(Md Sohannur, 2015).Figures1a and 2 show plain views of the most popular plain weave, which is the basis of many indigenous Ghanaian traditional woven fabrics such as the Bim'mayli cloth.

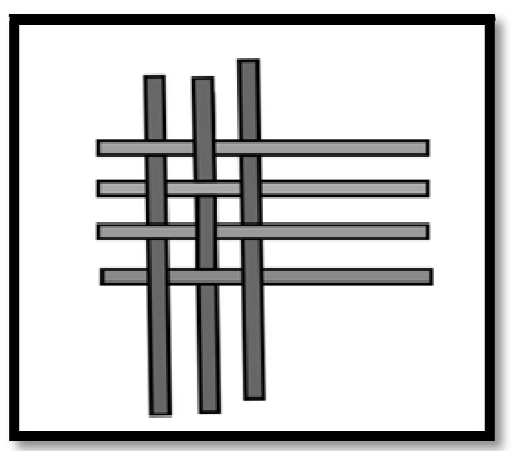

Figure 1: Plain Weave

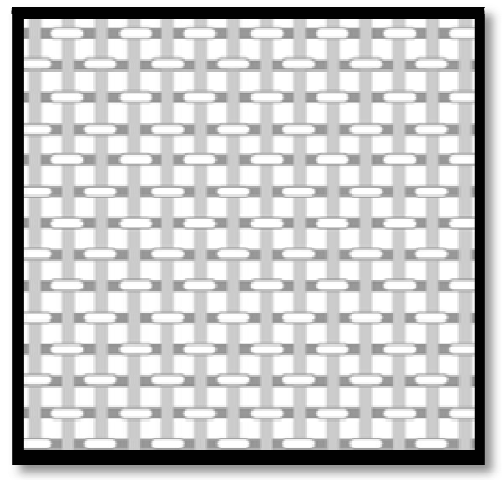

Figure 2: Plain Weave 
As seen in Figure 1, the filling threads pass over and under successive warp threads and repeat the same pattern with alternate threads in the following row, producing a chequered surface (Babu, Koushik, Lakshmikantha \& Subramaniam, 2011). They do not ravel easily but tend to wrinkle and have less absorbency than other weaves. The plain weave is variously known as calico or tabby weave. It is the simplest of all weaves having a repeat size of 2 . Similarly, the Bim'manli cloth is basically a plain weave structure and its indigenous weaving style consists of one coloured warp pattern stretched on the loom with another weft yarn of the same or different colour than the war inserted across the whole length of the warp yarns. Even today, the same weaving style is done but with the people desire for wearing Bim'ma $l i$ cloths with many colours, there have been innovations into the indigenous characters of the Bim'ma li cloths.

\subsection{The Strip-Cloth Loom and Accessories}

Narrow strip looms were the main indigenous looms used for weaving in Ghana. However, due to the recent advent of technology, other types of looms with modifications in accessories have been made and used among some weavers in Ghana (Frimpong \& Asinyo 2013). The Dagombas' Bim'ma li cloth weaving is still practiced on narrow strip looms. Though other looms are invented and used in Ghana, the narrow strip loom is the main device used by the weavers to produce strip-woven cloths in Ghana. Frimpong and Asinyo expound further that these looms used by the weavers are in different shapes, sizes and heights depending on the weaving locality and the creativity of the weavers.

The traditional narrow loom is normally a box-like wooden structure in which the weaver sits to weave. It is usually, among all weavers across Ghana, made of double-heddle looms that mostly have two or four heddles. In the Northern part of the country, traditional narrow looms have two heddles while most looms in the Southern and Volta regions are composed of four heddles (Badoe \& Opoku- Asare 2014; Sabutey 2009). Bim'mayli looms are fundamentally simple frames that hold a set of yarns in tension; they have no warp beam hence weight is used to give tension to the warp yarns during weaving.

Likewise, Frimpong and Asinyo (2013) state that, 'Found in the Ghanaian society, strip loom is a narrow doubleheddle portable loom, mounted on a simple semi-permanent frame' (P. 5). They explain further that this makes it removable coupled with the fact that the loom can be dismantled and re-assembled at any time which allows the weaver to move from village to village looking for orders. Frimpong and Asinyo conclusively purport that the most advantageous aspect of the traditional looms in Ghana to the weavers is the fact that they are quickly dismantled in the raining seasons whenever rain threatens to fall, or to pack up after a weaving session

The loom (Kpalu dari) among the Dagombas is similar to that of the Asante and the Ewe people. Most of the looms are the immovable types constructed with wood. The looms are locally constructed by the weavers themselves out of wood cut from the bush. The looms constructed among the Dagombas are the simplest in terms of structure (Frimpong \& Asinyo 2013). They are made up of two front posts which are Y-shaped with a stick across to support the tensioned warp yarns and the reed and the heddle are connected to the roof of the shade with a string. These wooden structures of looms are normally fixed in the earth and after the day's work; the accessories of the loom are dismantled and taken home.

The accessories are basically the equipment that are separated from the loom for the production of the cloth. These include bobbins, shuttle, bobbin winder, shed sticks, spool rack, skein winder, heddle, reed, pulleys, among others. The accessories of looms among the various strip-cloth weavers in Ghana have vast similarities with few differences. The differences are seen in terms of the shapes, sizes and composition of the accessories (Badoe \& Opoku-Asare 2014; Frimpong \& Asinyo 2013). Badoe and Opoku-Asare added that the accessories have unique names and meanings which are peculiar to the various cultures. The pulleys designed by the Ewes are sometimes carved in figurative forms and become culturally unique among them. The carvings on other accessories make them unique but they basically perform the same functions.

\section{Data Collection}

Data for this qualitative study were gathered through direct observation of indigenous Dagomba Bim'manli weaving processes at E.P College of Education, Bimbilla in the Northern Region of Ghana and interviews conducted with teacher trainees and traditional master weavers. The next stage was exposing the teacher trainees to hands-on-activities on the weaving of the Dagomba Bim'mayli cloth to demonstrate the possibility of teacher trainees' acquisition of skills in weaving that will enable the mcarry out quality teaching and learning of weaving and stitching at the basic level of education in Ghana. The population for this study comprised 86teacher trainees and 6 traditional master weavers. The teacher trainees are Elective students in Art of E.P College of Education (Bimbico)for the 2017/ 2018 academic year, whose second semester project for the course,' Weaving and Stitching', was to prepare and weave a two-yard 'guineafowl' Bim'manli cloth in their groups. This elective class comprised majority of students who had no background knowledge in textiles from Senior High School and a few who had prior learning in other Visual Art subjects but not textiles. How ever, a few of the students have learnt how to weave the Bim 'ma $l i$ cloth from their masters.

\subsection{Processes Involved During the Weaving of the Bim'mayli Cloth}

The teacher trainees underwent several processes involved in weaving the Bim'ma li cloth, and the first most two important stages were idea development and preliminary designing.

\subsubsection{Idea Development}

Students were guided on how to create new weaving patterns from existing woven patterns or from any other pattern that can generate a woven pattern. The students comprised of four groups and each group created patterns for their own. In this stage, the students went through a lot of observations in order to have broad knowledge about different 
styles of laying the warp yarns so as to create different patterns. They developed sketches from known ones and at the end they got ideas about how to construct patterns. See the creation of some selected patterns through idea development by the teacher trainees in Figure 3.

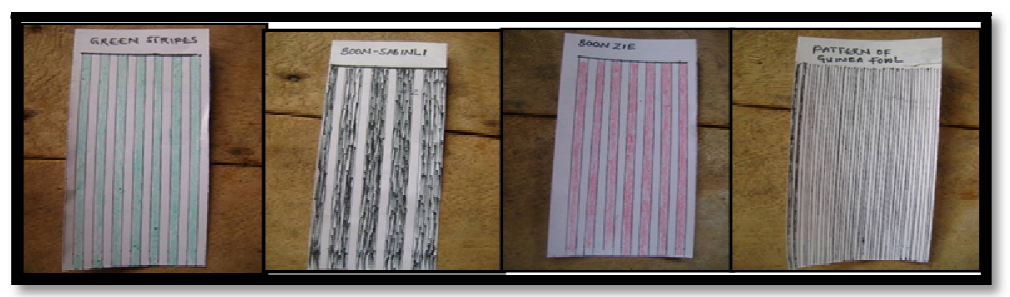

Figure 3: Idea Development

\subsubsection{Preliminary Designing}

Under this stage, the teacher trainees created several examples of the patterns of guineafowlBim'manli cloth of their choice to be woven. They created the replicas of their final semester's projects of a woven Bim'manli cloth in two yards so that they will be assessed by University of Cape Coast. See some examples of preliminary sketches selected among the teacher trainees in Figure 4.

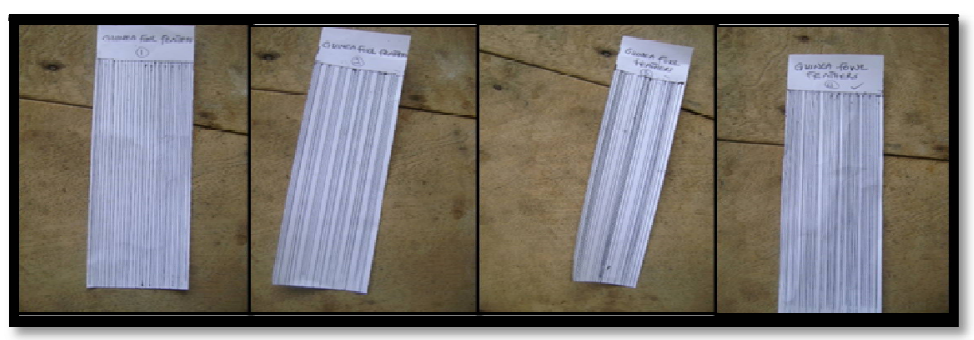

Figure 4: Preliminary Sketches

\subsection{Preparing Bobbins}

The teacher trainees went through the processes of unwinding skeins, cheeses and cones onto bobbins by using the skein and bobbin winders. These activities were carried out so that the teacher trainees will get yarns for warping and for filling yarns. Figure 5 portrays the teacher trainees carrying out the bobbin preparations.

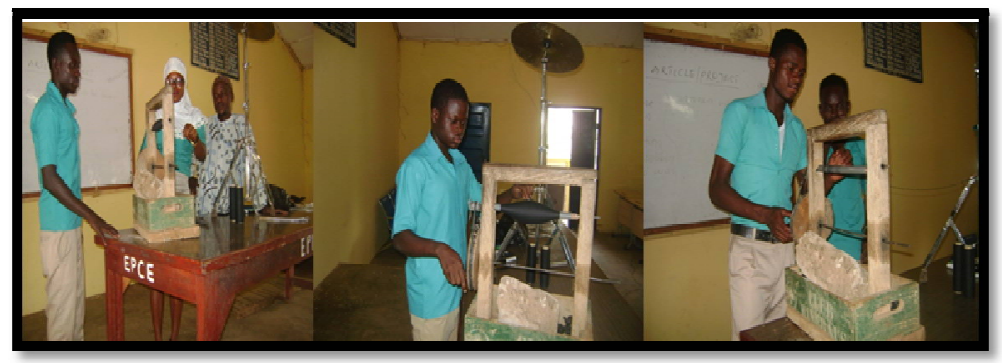

Figure 5: Bobbin Preparation

\subsection{Warping}

Before warping is done, there searcher guided the trainees to calculate the size of the cloth to be woven. This is done by considering the width of the warp beam which is calculated by the number of yarns to be propelled around the pegs. This also depends on the number of rounds that the weaver will make with each colour of yarn on the bobbins

Bigger bobbins known in Dagbani as kahwuhisi are used for warping after the skeins or cones have been unwound onto them. During warping, the teacher trainees inserted pegs at the appropriate distances and with the spool rack, they walked around the pegs and the bobbins rotated to propel yarns around the pegs as depicted in Figure 6. 


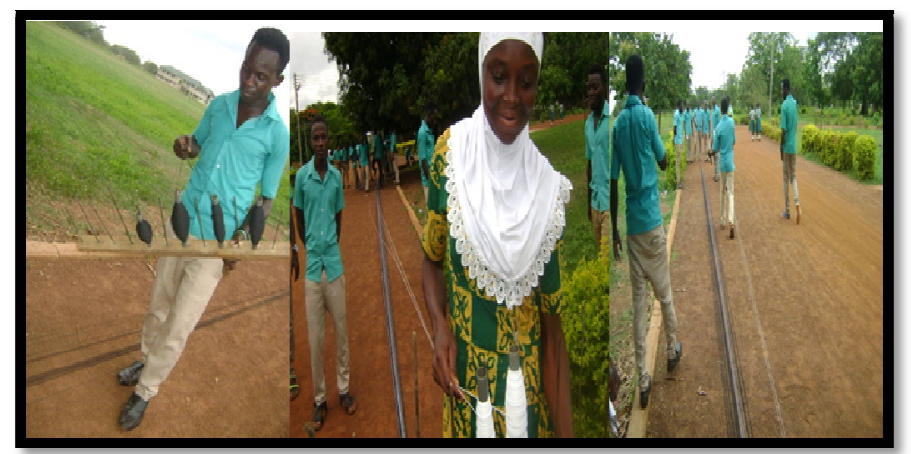

Figure 6: Warping

After stretching the warp yarns (warping), the warp beam is collected by folding it in the traditional way (see in Figure 7 below).

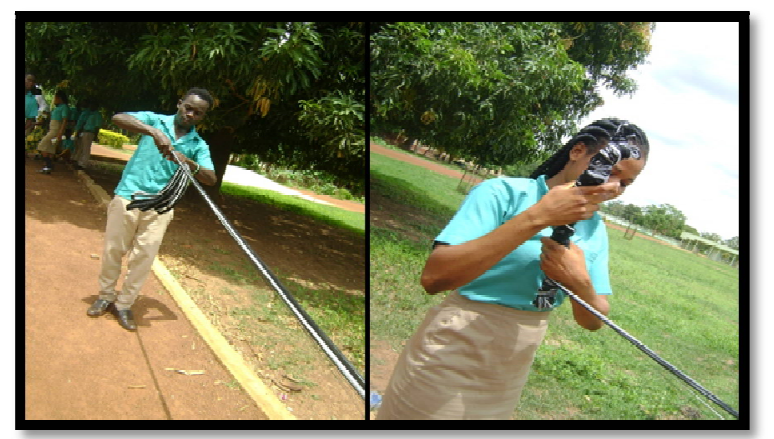

Figure 7: Collecting (Coiling) The Warp Beam

\subsection{Heddling}

Here, the teacher trainees were guided through the process of passing the individual warp yarns through the healds of the heddles. As the Dagomba Bim'mayli cloth loom has two heddles, the warp yarns are passed through the healds of the two heddles in alternating order so that during peddling, two separate warp yarns are opened to create the shed for the insertion of the weft yarn. See heddling processes in Figure 8 below.

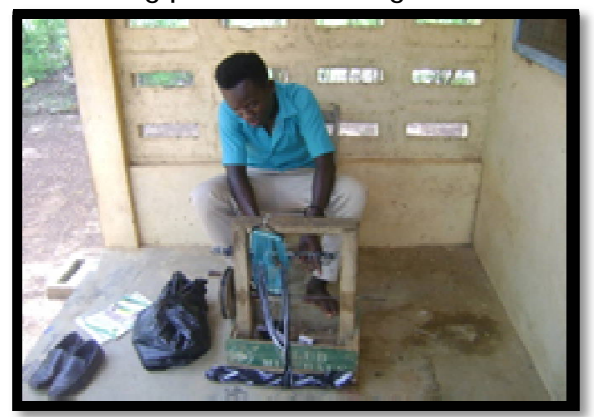

Figure 8: Heddling

\subsection{Reeding}

After heddling then comes the process of reeding in which the ends are passed through the dents of reed as they emanate from the heddles. In both the heddles and the reed, the ends are centered through the center so that there is stability of the heedless and reed.

\subsection{Tie-up}

Tie-up refers to the way the shafts are tied to the treadles on the loom. The teacher trainees were guided to do tieup so that they will learn to know that, to open a shed, a treadle must be depressed and because they are tied to the shafts (heddles), they cause one of the shafts to be lowered and the other to be lifted up. The shafts or heddles carry the healds on which the ends are suspended; this causes the ends to be divided into two sheds.

\subsection{Weaving}

The teacher trainees were taken to learn how to insert weft yarns through the shed. In the weaving process, two treadles are used and each is connected to a heddle. When a treadle is depressed, it creates a shed. A weft thread is then propelled through the shed with the shuttle and the newly inserted weft is also beaten to the fell of the cloth. When the fell of the cloth becomes long (extended beyond the weaver's hand at the fell of the cloth), it makes insertion difficult, therefore, the cloth beam is rolled onto the cloth beam stick (Bamdohu) by pulling the kpaanjili(ratchet pawl). When weft yarns are finished in the shuttle (Gombo), a new weft bobbin (Kukonli) is replaced. The process is repeated over and over 
till the required length of cloth (yard) is woven. See teacher trainees in Figure 9 executing the weaving of the Bim'ma ${ }^{\prime}$ li cloth.

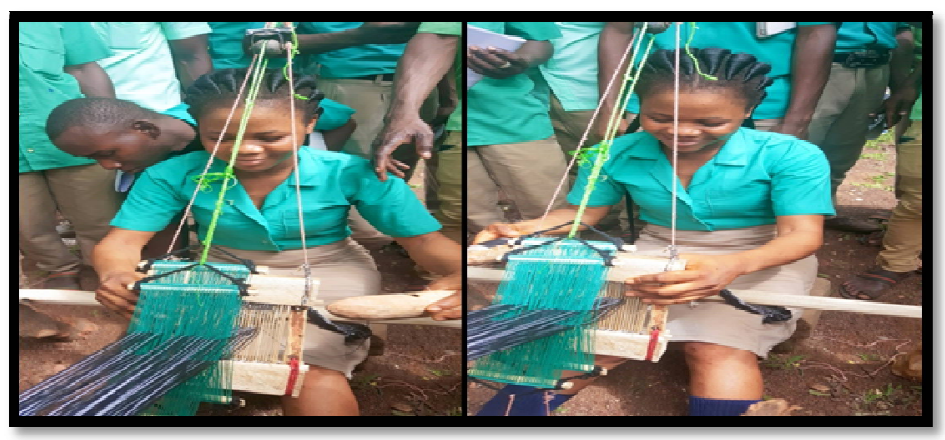

Figure 9: Weaving Process

\section{Findings and Discussion}

This section presents the findings and discussion of the data gathered from the field. The discussion has been organized into sub-sections to reflect the key issues identified.

\subsection{Demographic Characteristics of Respondents}

The male teacher trainees in Table 1 are 68(79.1\%) and the female teacher trainees are 18(20.9\%). This shows that there are more male teacher trainees offering an elective in art than the female students. This according to Solomon and Opoku-Asare (2012) could be attributed to the fact that the society lacks knowledge in art to give proper counseling to students, and more especially girls (S.K Amenuke, personal communication, February 18, 2018) which make the girls fear drawing than boys. This makes girls turn to choose other courses than art in schools.

In Table 1, 7(8.1\%) teacher trainees offered Visual art courses in the Senior High School, 79(91.9\%) teacher trainees offered non Visual Art courses. It portrays the fact that the few students who choose to offer Visual arts courses in the Senior High Schools do not even perform well in their final exams. This issue is attributed to the finding that the Basic Design and Technology (BDT) subject studied in the Junior High Schools has great challenges in terms of logistics in teaching and learning (Osei-Opoku \& Yeboah Okrah, 2017) and leads to many students not choosing to offer Visual Arts in Senior High Schools in Ghana.

Table 1 also indicates that 1(1.2\%) teacher traineeis a master weaver in Bim'mayli weaving, 2(2.3\%) are apprentices inBim'mayli weaving, 2(2.3\%) had knowledge in kete weaving, and 81(94.2\%) have no idea about traditional fabric weaving on the loom in Ghana. This means that only 5(5.8\%) teacher trainees have idea about traditional fabrics weaving. This explains the fact that the youth in school does not cherish much in taking up the weaving of the Bim'manli, kente and kete as vacations that can offer them financial freedom to supplement their teaching professions. This may also be attributed to the fact that majority of the youth who are weavers in the Bim'mayliat home are having poor Senior High School certificates to enter into Colleges of Education in Ghana.

\begin{tabular}{|c|c|c|}
\hline Information & Frequency & Percentage (\%) \\
\hline \multicolumn{3}{|l|}{ Sex: } \\
\hline Male & 68 & 79.1 \\
\hline Female & 18 & 20.9 \\
\hline Total & 86 & 100.00 \\
\hline \multicolumn{3}{|l|}{ Course read at SHS: } \\
\hline Visual Arts & 7 & 8.1 \\
\hline Non Visual art courses & 79 & 91.9 \\
\hline Others (specify) & - & - \\
\hline Total & 86 & 100.00 \\
\hline \multicolumn{3}{|l|}{ Teachers' Background Knowledge in Bim'ma gli Weaving: } \\
\hline Master weaver in Bim'ma li cloth weaving & 1 & 1.2 \\
\hline Apprentice in Bim'ma li weaving & 2 & 2.3 \\
\hline Knowledge in kente or kete weaving & 2 & 2.3 \\
\hline in Ghana & 81 & 94.2 \\
\hline Total & 86 & 100.00 \\
\hline
\end{tabular}

Table 1: Demographic Characteristics of Respondents 
4.2. Traditional Master Weavers' Views on Rules Governing the Weaving of the Bim'ma li Cloth

\begin{tabular}{|c|c|c|}
\hline Information & Frequency & Percentage (\%) \\
\hline $\begin{array}{c}\text { Are therestringent rules governing the } \\
\text { weaving of Bim'mayli cloth among the } \\
\text { Dagomba? }\end{array}$ & & \\
\hline Yes & 1 & 16.7 \\
\hline No & 5 & 100.3 \\
\hline Total & & \\
\hline $\begin{array}{c}\text { Are females forbidden to weave Bim'mayli } \\
\text { cloth among Dagomba? }\end{array}$ & 0 & 0 \\
Yes & 6 & 100 \\
\hline No & $\mathbf{6}$ & 100.00 \\
\hline Total & & 0 \\
\hline Can the traditional loom be mounted in & & 100 \\
schools for teaching and learning? & 0 & 100.00 \\
Yes & 6 & $\mathbf{6}$ \\
\hline No & & \\
\hline Total & & \\
\hline
\end{tabular}

Table 2: Responses from 6 Traditional Master Weavers

In Table 2, 1(16.7\%) traditional master weavers responded yes to the question as to whether there are stringent rules governing weaving of the Bim'mayli cloth or not, while 5(83.3\%) of them responded no to the question. This clearly shows that the weaving of the Bim'mayli cloth does not go with strict rules that can forbid any person who wants to go into the business of Bim'mayli production and marketing.

The one traditional master weaver who testified that there are stringent rules governing the weaving of the Bim'manli cloth only madetestimony toa past conscience that women on mensuration should not sit among men. This then affected those women who were weavers to isolate themselves from men in the shed so that there will not be spiritual infections to these women. However, the majority of the traditional master weavers testified that this belief among menstruation women is nullified by other belief systems from Christianity and Islam which both forbid people worshipping and believing in spiritualties, deities or lesser gods. Hence, 5(83.3\%) in Table 2 accepted that women who are menstruating today are not forbidden to weave among the men.

The absent of stringent rules governing the weaving of the Bim'mayli cloth has also made it freelance for the researcher to teach it in E.P College of Education, Bimbilla without entertaining any fears. This goes to confirmall the 6 traditional master weavers' response in Table 2 that the loom for weaving the Bim'magli cloth can be mounted in schools for practice without any bridge of traditional beliefs or practices.

\subsection{Observations Made on Teacher Trainees during the Bim'ma $l i$ Cloth Production}

\begin{tabular}{|c|c|c|c|c|}
\hline Reactions/ Attitudes & Poor & Good & Very good & Excellent \\
\hline Critical thinking & & & $\checkmark$ & \\
\hline Punctuality & & & & $\checkmark$ \\
\hline Creativity & & & $\checkmark$ & \\
\hline Understanding & & & $\checkmark$ & \\
\hline Handling of tools/ materials/ equipment & & $\checkmark$ & & \\
\hline Females' level of participation & & & & $\checkmark$ \\
\hline
\end{tabular}

Table 3: Reactions/ attitudes

In Table 3, teacher trainees' critical thinking level was rated very good. This indicates that when learners are exposed to hands-on-activities, they develop critical thinking skills. This fact is further buttressed by Yildrim (2001) that making students to explore with tools and materials promotes their ability to think critically in solving problems. Right from the idea development stage, teacher trainees explored high level of thinking to come out with different patterns of Bim' mayli cloths. In the weaving processes as well, teacher trainees exhibited high spirits of thinking as to how to freely open the shed and insert picks continuously.

Punctuality was another observable attitude which was rated excellent. A register of attendance was cross checked during the teaching and learning periods and it was found out that $98 \%$ of the teacher trainees were always present in each lesson. The few absentees always sought permission to attend to other pressing issues such as visiting the bank and hospitals for their allowances and health issues respectively. This clearly proves that when teaching and learning is practicalised students get motivated to always be part of the hands-on activities in which they appear to learn by doing (Susak, 2016) and Jennifer (2011). 
Creativity was also rated very good. It was found out that teacher trainees were able to transfer their previous knowledge acquired in first year foundation classes into the second year course. This means that when teaching and learning is made interactive and with the use of appropriate teaching and learning materials, students stand the chance of retaining a greater percentage of knowledge in what they learn. This also supports the fact that tutors need to coach learners well (Aziz, Quraishi \& Kazi, 2018), so that when the aim is for the learners to transfer their knowledge and skills to new situations, they stand the chance of remembering what was learnt previously. The teacher trainees showed good skills in innovativeness or originality and this remains one of the standards for students' assessment in Visual Arts (Fiadzo, 2010).

The teacher trainees' level of understanding was also rated very good. The researcher observed that after the tutor's demonstration of the weaving processes on the loom, the trainees were capable to be on their own, though with minimum support from the tutor, till the project was finally executed. It was also found out to be as the result of the influence of the master weaver among the teacher trainees who waspart of the elective class. This obviously shows the impact of peer influences on students' learning abilities as indicated by Ampadu (2011) and Dulonsky et al (2013)that student-centered approaches enable students to interact among themselves to solve problems on their own.

In Table 2, the teacher trainees' ability to handle tools and materials was rated to be good. It was found out that they needed enough time to be conversant with the use of tools and materials for weaving. This is as a result of majority of them being lay persons in the Bim'mayli cloth weaving as well as being non Visual Art students. Therefore, the teacher trainees' reaction with the weaving tools and materials is progressive. This supports Cabrillana and Mayan (2017)as well as Beaman Wheldall(2000) indication that teachers must consider the learning pace of individual students because most classrooms are mixed abilities classrooms.

The participation of female teacher trainees was rated excellent. The tutor observed that the few female counterparts were very active in all processes involved in producing the Bim'manli cloth. This points out to the fact that female students can equally do what their male counterparts can do in the teaching and learning diaspora within Colleges of Education, hence equal opportunities should be given to female teachers in classroom management and learning affairs. Zakaria, Chin, and Daud (2010) enforced this teaching strategy by indicating that teachers should provide equal chances for all learners in class to promote effective teaching and learning and gender equity.

\subsection{Teacher Trainees' Reactions/ Attitudes after Production}

\begin{tabular}{|c|c|c|c|}
\hline Reactions/ Attitudes & Yes & No & Total \\
\hline $\begin{array}{c}\text { Visit master weavers/ elders at home during } \\
\text { Easter break to enhance their skills in } \\
\text { weaving the Bim'manli cloth. }\end{array}$ & $65(75.6 \%)$ & $21(24.4)$ & $100 \%$ \\
\hline $\begin{array}{c}\text { Students continued practicing weaving on } \\
\text { the loom mounted in the school }\end{array}$ & $76(83.4 \%)$ & $10(11.6 \%)$ & $100 \%$ \\
\hline
\end{tabular}

Table 3: Post-Reactions/ Attitudes of Teachers

In Table 3,65(75.6\%) of the teacher trainees visited master weavers and elders at home during Easter Break within the second semester to learn more about Bim'mayli weaving. This makes learning a continuous process as students go beyond the classroom to acquire more in-depth information about what is learnt in class. According to the reasons given by the respondents who could not visit master weavers for more information regarding Bim'manli weaving, that they stayed at places where weaving is not done. This shows that the art of traditional weaving is not a full time occupation practiced in some villages and towns in Ghana. In most villages, farmers will remain very active on their farms than any other business during the raining season, hence most weavers in villages stop weaving until farming activities are minimized. This is related to Frimpong, Asinyo and Amankwah's (2016) view that the cotton cultivation in the northern part of the country which feeds the textiles factory dwindles because of farmers' desire for food crops cultivation than cotton.

In Table 3, it also showed that $83.4 \%$ of teacher trainees continued practicing the Bim'mayli weaving on the loom after the main project was over. This is usual with students subjecting the facilities to use when learning facilities are made conducive and available to them (McGowan, 2007). From the view of some of the respondents, it was found out that the teacher trainees needed to improve upon their skills of weaving so that they can supplement their teaching professions with Bim'mayli weaving after they finish school. This is why Fusheini and Bukari (2017) indicate that art offers students self-employable skills to uplift their economic status.

\section{Conclusions}

In teaching a skill in a practical course area like art, tutors in Colleges of Education should adopt teaching and learning processes that completely fall under the learning by doing principle. In exposing the teacher trainees' independent execution of weaving the Bim'ma $l i$ cloth, they developed very necessary critical thinking skills which offered them abilities to solve problems in life. The teacher trainees' interactions with master weavers in their communities have helped them acquired much knowledge about the material culture of their people which will enhance their understanding of the environment. This will help them cope with many norms in the societies where they will be doing their teaching practices as well as their final postings.

The Bim'manli weaving is a major traditional handicraft among the Dagomba people and it does not have strict rules exempting females from the job. This is as a result ofthe fact that the Dagomba women were earlier on the pioneers 
in making fabrics by weaving and stitching for the homes coupled with the fact that Christianity and Islam have denounced a lot of practices in occultis msuch as forbidding women for certain roles in life.

The teacher trainees in the elective class had majority of them who did not offer Visual Arts in the Senior High Schools. One of the reasons is that majority of parents or guardians are never ready to applause art education in the midst of the children due to lack of knowledge about art. Also, female teacher trainees took active participation in the weaving processes in order to gainmuch experience in Bim'mayli cloth weaving. They exhibited competitive skills with boys and produced very intricate paper designs and weaves. This resulted from the fact that gender equity has received a great concern in recent times for the economic enhancement of women in all fields of endeavor.

\section{References}

i. Fiadzo, S.V. (2010). Weaving techniques in colleges of education using a variety of media (Master's thesis, Kwame Nkrumah University of Science and Technology). Retrieved from http:/ / citeseerx.ist.psu.edu/ viewdoc/ download?doi=10.1.1.838.1226\&rep=rep1\&type=pdf

ii. Abugri, G.S (2016, April 19). 'The Fugu Dr. Nkrumah gave the world', Daily Graphics. Retrieved from http:/ / www.sydneyabugri.com/Web/index.php?option=com content\&view=article\&id=218:the fugu-drnkrumah-gave-the-world\&catid=39:other-resources\&Itemid=152

iii. Abugri, G.S (2017). A cultural point of order: A fugu not a batakari, Ghana Government, Accra.

iv. MOE (2012). Basic design and technology syllabus for JHS. Accra: Ministry of Education.

v. Essel, O.Q\& Amissah, E.R (2015). Smockfashion culture in Ghana's dress identity-making. Historical Research Letter, 18(2225-096), 32-39.

vi. Jasmine, A (2016, June 14). Fugu-the Tradition goes on', Graphic Ghana. Retrieved fromhttp:/ / www.graphic.com.gh/ features/ features/ 11044-fugu-the-tradition-goes-on.html

vii. News Ghana (2015, March 4). The priceless traditional attire, batakari. News Ghana. Retrieved from http:/ / www.newsghana.com.gh/ the-priceless-traditional-attire-batakari

viii. Tettehfio, L.A. (2009). The role of the indigenous Ghanaian textile industry in relation to the president's special initiative (PSI) on textiles and garments (Doctoral thesis, Kwame Nkrumah University of Science and Technology). Retrieved from

ix. http:/ / ir.knust.edu.gh/ xmlui/ handle/ 123456789/ 288?show=full

x. TEonline.com (n.d). Fabric construction, Retrieved from <http://www.teonlone.com/ knowledgecenterd/ fabric.construction.html>.

xi. Frimpong, C., \& Assinyo, B.K. (2013). A comparative study of history, equipment, materials, techniques and marketing approach of traditional weaving in Ghana. Arts and Design Studies, 3, ISSN 2224-6061(paper) ISSN 2225-059X

xii. Sabutey, G.T (2009). Aesthetics, Appreciation and Criticism among Indigenous Asante Kente Weavers: Implications for Art Education and National Development.(Doctoral thesis, Kwame Nkrumah University of Science and Technology).Retrieved from http:/ / ir.knust.edu.gh/ bitstream/ 123456789/ 791/ 1/ Gordon\%20Terkpeh\%20Sabutey.pdf

xiii. Onder, E \& Omer, B.B (n.d).Weaving Technology II. Basic Operations in Weaving Process. Retrieved from $<$ Łttp:// web.itu.edu.tr/ berkalpo/ Weaving_Lecture/ Weaving_Chapter1a_06S.pdf>.

xiv. Unal, PG (n.d).3D wove fabrics, Intech, Namik Kemal University, Turkey.

xv. Textile Fashion Study (2012, September 5). Plain weave/ / Properties of plain weave// Ornamentation techniques of plain cloth. Retrieved from http:// textilefashionstudy.com/ plain-weave-properties-of-plain-weaveornamentation-techniques-of-plain-cloth/

xvi. R. Md Sohannur (2015, February, 27). Derivatives of plain weave. Retrieved from https:/ / textilestudycenter.com/ derivatives-of-plain-weave/ ?upm_export=pdf

xvii. Babu, V. R et al. (2011). Influence of the weave factor on the character of fabric wicking measured by a multiple probe vertical wicking test. FIBRES \& TEXTILE in Eastern Europe, 19(5), 60-63

xviii. Badoe, W \& Opoku-Asare, N. A 2014, 'Structural patterns in Asante kente: an indigenous instructional resource for design education in textiles', Journal of Education and Practice, 5(25), 52-63,

xix. Solomon, F.E., \& Opoku-Asare, N.A. (2012). Girls' motivation, participation and performance for Visual Arts subjects in four Senior High Schools in central region, Ghana. Journal of Science and Technology, 9(3), 118-128.

xx. Osei-Opoku, P. \& Yeboah Okrah, B. (2017). Assessment of teaching and learning activities of Basic Design and Technology in selected Junior High Schools in Ashanti Region. British Journal of Education, 5(6), 1-12.

xxi. Yildrim, B. \& Ozkahraman, S. (2011). Critical thinking in nursing process and education. International Journal of Humanities and Social Science, 1(13), 257-262.

xxii. Susak, M. (2016). Factors that affect classroom participation (Master's thesis, Rochester Institute of Technology). Retrieved https:/ / scholarworks.rit.edu/ cgi/ viewcontent.cgi?referer=https:/ / www.google.com/ \&httpsredir=1\&article=105 26\&context=theses

xxiii. Jennifer, S. M. (2011). The impact hands-on experiences have on interest and attitudes of middle school science learners (Master's thesis, Ohio University). Retrieved from https://www.ohio.edu/ education/academicprograms/ teacher-preparation/ department-of-teacher-education/ mastersprograms/ loader.cfm?csModule=security/ getfile\&amp;PageID=2184610 
xxiv. Aziz, F; Qurasihi, U. \& Kazi, A.S. (2018). Factors behind classroom participation of Secondary School (A gender based analysis). University Journal of Educational Research, 6(2), 211-217.

xxv. Ampadu, E. (2011). Does peer influence affect students' participation in Mathematics? International Online Journal of Educational Sciences, 3(2), 424-434.

xxvi. Dunlonsky, Y. J., Rawson, K.A, Marsh. E.J, Nathan,M.J., \& Willingham, D. T. (2013). Improving students' learning with effective learning techniques: Promising directions from cognitive and educational psychology. Psychological Science in the Public Interest, 14(1), 4-58.

xxvii. Cabrillana, A.H. \& Mayan, C.L (2017). Teaching styles and achievement: Student and teacher perspectives. Retrieved from https:/ / www.uma.es/ media/ tinyimages/ file/ 20170331.pdf

xxviii. Beaman, R. \& Wheldall, K. (2000). Teachers' use of approval and disapproval in the classroom. Educational Psychology 20(4), 431-446.

xxix. Zakaria, E., Chin, C.L. \&Daud, Y. (2010), The effect of cooperative learning on student mathematics achievements and attitudes towards mathematics, Journal of Social Sciences, 6(2):272-275. Available on <http:// dx.doi.org/ 10.3844/ jssp.2010.272.27.

xxx. Frimpong, C, Asinyo, B. \& Amankwah, E (2015). The state of cotton production in northern', Ghana Internal Journal of Fibre and Textiles Research, 5(4),58-63.

xxxi. Fusheini, M. Z\& Bukari, M. (2017).Materials and methods for producing basic instructional support resources for teaching creative arts in Zohe Evangelical Presbyterian Primary School, Yendi Ghana. Journal of Education and Practice, 8(34), 83-96. 